taught to do so and because there is little in the peacetime social evolution of the present century that is designed to evoke a sense of personal responsibility, and much that leads to a demand for rights and benefits with little reference to the need for a corresponding in-put of duties and obligations. But most people have an inherent sense of fair play, and in the end if they are properly guided it becomes dominant in their way of living, so there is no need for despair. The material is there if we can only evoke it. In healthy people this is ultimately a matter of self-examination and of conscience; it cannot be considered in its entirety only on a materialistic economic plane; it is inseparable from fundamental conceptions of right and wrong. And somehow it seems from the evidence, that the churches-whose part in this is surely obvious - and the people, have got pretty far apart in many ways. It is not for me to intrude upon their ground; but that the churches have a part to play, and in my view an indispensable one, in the interpersonal relationships of people and so in the prevention of misfits there can be no possible doubt.

\title{
A Mental Health Exhibition
}

\author{
By M. W. HAMILTON \\ Regional Organizer (Region 2), National Association for Mental Health
}

How can you best present a Mental Health Exhibition?

This difficult question is yet to be answered, but the Leeds Public Health Department made an interesting move in this direction with their Mental Health Fortnight, held last June in central premises, occupied by the Central Council for Health Education. During previous fortnights, various aspects of Public Health, for example Maternity and Child Welfare, Food, Care of Eyes and Teeth, etc. had been on show.

One main window of a shop and two side ones needed to be filled in some way and inside one long Display Board and three small alcoves. Downstairs there was a small cinema.

This was the framework within which we had to work, but otherwise we had a free hand. We did not know of anything in the way of recent precedent, so the Public Health Department along with the National Association for Mental Health, and the University Department of Psychiatry, had to plan from their own ingenuity. Preliminary discussions revealed how short we were of anything that could be called "show material," and in view of limited funds how difficult it was to translate ideas into effective visual shape in this particular field.

In the end it was decided to concentrate on the Mental Health of Childhood as the subject for the main window, with a series of supporting photographs inside, reserving the side-windows and the three interior bays for displaying the rugs, toys, etc., made by the patients at the local Mental Deficiency Colony and the Mental Hospital. There were also inside, a series of photographs illustrating life in the Colony under the heading "Training the Mentally Handicapped". Two posters showing the incidence of neurosis in ill-health generally and the incidence of morbid mental states in the population at large, with two posters from the Bureau of Current Affairs having a bearing on overcrowding in cities and on neighbourliness, completed the wall display. By the door was a notice stating that in any question of Mental Health the following could be consulted: The Doctor, The Leeds Mental Health Services, The University Department of Psychiatry, and the Regional office of the National Association for Mental Health (addresses given).

The arrangement of the main window proved rather a teaser. We would have liked something in dramatic model form to catch the eye, but the question was what? In the end, we had to content ourselves with an arrangement of posters mounted on supports, at three levels, the first two from the N.A.M.H. series, "My Goodness what patience Mothers need"; the second two specially drawn for the show-"Children's awkward Questions", and "How do you appear to your Child?"and the third series, a painted frieze of children running and playing, which acted as a backcloth, notices as to the Cinema Show, and times of . opening, and the series of Parent Guidance booklets published by the N.A.M.H. completed the frame. The contents of the window were covered by the slogan-" Mental Health begins at Home".

Inside, this idea was carried a little further by a series of photographs showing the individual child at various stages from birth, in the Nursery School Group, and in adolescence; these had suitable captions, and the theme was that "For a good start he needs breast-feeding, and to move, see, do and eat in his own time and his own way, in an atmosphere of affection and security". This covered the first series of photographs. The second suggested the theme that " through his play in the nursery group the child learned his social 
skills and his mind grew". The third series suggested the need for creative and physical outlet for the adolescent, and in between was inserted a small group of photographs illustrating treatment in a Child Guidance Clinic. This, with a small table for the display of literature together with the objects made by the Colony and Hospital patients, completed the show.

The three films chosen finally out of a rather small available range and shown at hourly intervals were : "The Children of the City," "Your Children and You," and "Fear and Peter Brown."*

How successful were we ? 1,500 people attended, a very great number more halted outside. The literature sold freely, and the photographs obviously interested and amused the majority, who were also surprised and somewhat envious of the high standard of craft shown by the exhibits from patients. From what comments we could hear, the cinema was found interesting, though in the phrase of one visitor (an ex-foreman engineer), "It's a bit airy-fairy-you University people don't know much about what's what !"

It was felt by all of us that the adult aspect of mental health was of necessity rather poorly served, as finding suitable material for this had defeated us, and it will remain one of the problems to tackle next time. We also learned that there is need for more emphatic and more colourful presentation if the points are really to be punched home.

Finally the old truth was again exemplifiedthat money is the important factor, and that given adequate funds, really exciting prospects are opened up (payment of artists, suitable models, premises, etc.).

One or two additional points for the future seem to be that it is advisable to have present throughout the time of exhibition someone who is well acquainted with mental health problems; another that there is perhaps scope for a mobile exhibition, which could visit various parts of the town, or the rural areas as well; and lastly, there seem indications that there was scope for a Central Health Exhibition on a much larger scale, where the different aspects of health could all be shown at the same time.

\section{WINTER CONFERENCE ON MENTAL HEALTH}

The National Association is arranging to hold a Conference on Mental Health at Seymour Hall, Seymour Place, London, W.1, on Thursday and Friday, January 15th and 16th, 1948.

The Conference will be addressed by Mr. L. John Edwards, O.B.E., M.P., Parliamentary Secretary to the Ministry of Health.

The programme will be as follows :

Thursday, January 15th

Morning: "Re-adaptation to Life and Work of Persons who have suffered from Nervous or Mental Disorders."

Afternoon : (a) "Methods of handling Difficult Children in Primary and Post-Primary Schools, as required under the Education Act, 1944.'

(b) "The Selection and Training of Staffs for Boarding Homes for Difficult Children."

Friday, January 16th

Morning: "The Responsibilities of Local Authorities in relation to Mental Health and the National Health Service Act, 1946."

Afternoon : "Education for Mental Health as a National and Int national Responsibility."

Speakers will include: Dr. G. R. Hargreaves, Dr. Donald Stewart, Miss E. M. Bartlett, Miss Clare

Britton, Dr. Kenneth Soddy, Dr. Doris Odlum, Brigadier A. Torrie, M.B., D.P.M., and Dr. J. R. Rees.

The Sessional Chairmen will be: The Rt. Hon. R. A. Butler, M.P., The Earl of Feversham, Prof. Sir Cyril Burt and Dr. W. Rees-Thomas (Senior Commissioner, Board of Control).

The Conference is supported by the relevant Government Ministries of the United Kingdom and Northern Ireland, and sanction is given to the payment of the expenses of delegates of Local Authorities appointed to attend the Conference.

The Conference fee, including the subsequent printed report of the proceedings, is $£ 15 \mathrm{~s}$. ( $£ 11 \mathrm{~s}$. for Full Members of the National Association for Mental Health), or $£ 1$ 1s. with the report (17s. 6d. for Full Members of the National Association for Mental Health). Sessional tickets 6s. each. Applications for tickets and all correspondence relating to the Conference should be addressed to: The Conference Secretary, National Association for Mental Health, 39 Queen Anne Street, London, W.1.

It should be noted that this Conference must not be confused with the World Congress on Mental Health to be held in London in August, 1948, and to which reference is made on page 49 of this issue.

* Produced some years ago by the Central Council for Health Education in co-operation with the National Council for Mental Hygiene. 